\title{
Website Atmospherics: Motivators Or Hygiene Factors?
}

James D. Mueller (Email: muellerj@cofc.edu), College of Charleston Rhonda Mack (Email: mackr@cofc.edu), College of Charleston

\begin{abstract}
Frederick Herzberg's two-factor theory is once again resurrected and used to frame hypothesized influences on internet shopper satisfaction (and dissatisfaction). Previous research investigating the influence of web site design and web site atmospherics is discussed with respect to the theory. Exploratory factor analysis is then used to extract a four-factor solution of internet shopper satisfaction, and interpreted with respect to Herzberg's model. Risk and User Friendliness related variables are interpreted as hygiene factors, or dissatisfiers, while Enjoyment and Price variables better explain shopper satisfaction, or motivation. The ensuing discussion compares the usefulness of this model with empirically validated satisfaction paradigms in explaining the relationship between internet shopper satisfaction and web site atmospherics.
\end{abstract}

\subsection{Introduction}

$T$

he rapid growth of e-commerce, or e-tailing, is making a major impact on both sides of the sales transaction. While this interaction is virtually between two computers, the human consumer and the organizational components are involved in planning, evaluation and decision making. Shoppers are finding a new, more convenient way to shop as they take on the challenge of their first e-tailing transaction while sellers are struggling to determine how to develop a successful e-tail storefront and how to cope with logistics issues arising as a result of recent sales increases.

E-commerce has been around since the beginnings of Electronic Data Interchange (EDI) in the 1970s. Increasingly, the term is used to refer to business over the internet involving on-line retailing instead of the earlier business-to-business transactions. Early e-commerce activity began largely with offerings from non-traditional internet companies without a physical store front or catalog business like Amazon.com. More recently, traditional retailers have seen great success in presenting their products to potential customers with the use of a computer, a browser, and internet access.

Numerous changes have taken place in e-tailing over its short life with vast improvements in products and services available, customer service enhancements, security measures, and ease of site navigation. The speed of these changes has caused major problems for businesses and consumers. One area of increasing interest in the area of internet retailing is labeled atmospherics.

Atmospherics are the physical elements in a store's design that appeal to consumer's emotions and encourage buying. The effects of elements such as store layout and design, lighting, music, and even odors have been widely researched in the retailing and consumer behavior literature. Because of the growth in internet access, more consumers are shopping on-line and more retailers (both traditional and web-based) are offering retail websites. Marketing research is increasingly being devoted to the cyberspace environment in general, and to the effects of website design on shopper behavior and satisfaction. This paper complements previous research in the field by applying Herzberg's (1968) two-factor model of job satisfaction to the field of internet shopping behavior. Particular

Readers with comments or questions are encouraged to contact the authors via email. 
attention is given to whether web-site embellishments, or atmospherics, fall into the category of hygiene factors (shopping dissatisfiers) or motivators (shopping satisfiers).

\subsection{Literature Review}

Theoretical constructs for this investigation span three main areas: the effect of retail environment on shopper attitude and behavior, the application of findings from traditional "brick-and-mortar" studies to web based shopping environment, and the application of a well-known management theory (Herzberg, 1968) consumer behavior. While the literature is resplendent with examples of the first category of research (see e.g. Bellizzi et al., 1983; Bitner, 1992; Bruner, 1990; Kellaris and Kent, 1992; Spangenberg, et al, 1996; Yalch and Spangenberg, 1990), studies investigating the web retailing environment are not only fewer, but are also lacking in consensus on appropriate models of shopper behavior. The third category of literature, applying the two-factor theory to consumer behavior in general, and to the web environment specifically, is even more sparse. As it is the purpose of this study to explore the applicability of Herzberg's model, a brief description of the theory is appropriate.

Frederick Herzberg (1968) developed a "two-factor theory" of motivation, which distinguishes dissatisfiers (factors that cause dissatisfaction) and satisfiers (factors that cause satisfaction). Dissatisfiers (also known as hygiene factors), for Herzberg, were found to stem more from the work environment, or context, while satisfiers pertained more to work, or job, content. More fundamentally, these two factors relate to two of man's most basic needs - avoiding pain (hygiene factors) and seeking pleasure (motivators). When applied to the workplace, the theory attempts to explain those variables that may be manipulated to increase job satisfaction. If hygiene factors are not taken care of, i.e., if dissatisfiers are not eliminated, workers will not be motivated. However, even if these dissatisfiers are eliminated, satisfaction will not necessarily follow, unless it is derived from the work itself. Viewed this way, hygiene factors are satisfaction (motivation) preventers, while the motivators are satisfaction inducers. Applying the model to the retail environment, hygiene factors are purchase preventers, while motivators are purchase inducers. Sellers need to work to not only eliminate dissatisfiers, but to identify and provide satisfiers as well. Retailers must also understand that even if dissatisfiers are eliminated, shoppers may not be induced to purchase if appropriate motivators are not present.

A multitude of studies have researched atmospheric variables such as crowding, colors, music, and odors in controlled experimental environments to determine effects on purchase quantity, time spent in store, likelihood of returning to the store, and overall shopping satisfaction. ) The isolated nature of most of theses studies point to a need for unifying research in order to capture potential interactions among the variables investigated. In response to this need, Baker's (1986) model of the retail environment categorized atmospheric variables according to three main factors: ambient factors, store design factors, and social factors. Similarly, Turley and Milliman (2000), categorize the retail environment according to external variables, internal variables, store layout and design variables, store decoration, and human variables, to explain the influence of the physical environment on shopping and purchasing behavior. While either model could be used, Baker's (1986) three factor model more simply summarizes potential atmospheric factors, their translation to the web environment, and potential effects on shopper behavior and satisfaction, as shown in Figure 1.

Because of the relative youth of the industry, fewer studies investigating the impact of website atmospherics on customer satisfaction and purchasing behavior can be found. Whether or not websites have atmospherics, and the impact they might have on web shopping behavior was the subject of Kelley's (2001) study. Here, Kelley (2001) investigated potential irritants of web site atmospherics by adapting the shopping irritants used by d'Astous (2000) and added four more irritants that appeared to relate to a web shopping experience. The adaptation of these potential irritants in a brick-and-mortar shopping experience to fit a web shopping experience necessitated rewording or rephrasing scale items, e.g. store crowding was rephrased as heavy internet traffic (Kelley, 2001), to reflect the different environments. While the results showed some similarity in factor structures between the traditional retail environment and the internet environment, the study focused on irritants (hygiene factors) and did not attempt to interpret factors as potential motivators. 
Perhaps the most relevant study attempting to apply Herzberg's two factor model to internet purchasing is Zhang and Von Dran's (2000) investigation of web-site design. Here, the authors postulate that hygiene factors make a website functional and serviceable while motivator factors add value. The former contribute to dissatisfaction, the latter to satisfaction. The authors identified twelve categories of variables, two of which were found to be motivators (Cognitive Outcome and Enjoyment), two were hygiene factors (Technical Aspects and Navigation), and the remaining eight were identified as both hygiene factors and motivators.

Figure 1: Influence of Atmospheric Factors on Shopper Behavior Satisfaction and Sales

\begin{tabular}{|c|c|c|c|}
\hline & $\begin{array}{l}\text { Ambient } \\
\text { Factors }\end{array}$ & $\begin{array}{l}\text { Store Design } \\
\text { Factors }\end{array}$ & $\begin{array}{l}\text { Social Factors } \\
\text { (organizational } \\
\text { interaction) }\end{array}$ \\
\hline $\begin{array}{l}\text { Traditional } \\
\text { Retail Environment }\end{array}$ & Music, odor, lighting & Layout, displays, traffic flow & $\begin{array}{l}\text { Employees, crowding, } \\
\text { waiting time }\end{array}$ \\
\hline $\begin{array}{l}\text { Web-Based } \\
\text { Environment }\end{array}$ & $\begin{array}{l}\text { Music, color, } \\
\text { graphics, animation } \\
\downarrow\end{array}$ & $\begin{array}{l}\text { Layout, design, navigability, } \\
\text { pop-up banners, etc. }\end{array}$ & $\begin{array}{l}\text { Download time, internet } \\
\text { traffic, chat rooms, sales rep }\end{array}$ \\
\hline $\begin{array}{l}\text { Intended Influence } \\
\text { On Shopper Behavior }\end{array}$ & Time-spent in store & $\begin{array}{l}\text { Increased store traffic, } \\
\text { impulse purchases }\end{array}$ & $\begin{array}{l}\text { Pleasant experience, return } \\
\text { to shop again, tell a friend }\end{array}$ \\
\hline \multirow{2}{*}{$\begin{array}{l}\text { Intended Business } \\
\text { Result }\end{array}$} & \multicolumn{3}{|c|}{$\downarrow$} \\
\hline & \multicolumn{3}{|c|}{ Increased satisfaction and sales } \\
\hline
\end{tabular}

Source: derived from Baker, 1986; Turley and Milliman, 2000, and d'Astous 2000; Kelley, 2001

Zhang and Von Dran's work is a major contribution to understanding website atmospherics, and supports the use of Herzberg's theory in explaining internet purchasing behavior. From the outset, the methodology used in their study was designed to apply Herzberg's model by categorizing variables as either motivators or hygiene factors. The respondents were briefed on the terminology before participating in data collection. While the ultimate goal of our paper is the same, the methodology is quite different. A wider range of shopping variables are included (ie. not just web site design variables), and the research instrument makes no reference to the Herzberg, as was the case with Zhang and Von Dran's work.

\subsection{Methodology}

A questionnaire designed to measure the source of internet shoppers' satisfaction and dissatisfaction was developed. Using the mall-intercept method, 188 usable questionnaires were collected. Respondents were prequalified according to whether or not they had shopped on the internet before. Quotas were set for the data collection in an attempt to include proportional representation of respondents in a number of demographic categories (see Table 1 for respondent information). Although additional information on degree of computer literacy, internet connection speed, and other items designed to build an internet shopping profile were also collected, the analysis of these items are beyond the scope of this paper. 
The original 25 scale items were reduced to 18 by eliminating ambiguous and weak loadings. The resultant measures of scale reliability $(\alpha=.72)$ and sampling adequacy indicate a good data set for exploratory factor analysis. Using the statistical package SPSS for windows, exploratory factor analysis was conducted on the purified data set, using principal component analysis with promax rotation with Kaiser normalization. The resultant scree plot indicated a four-factor solution was appropriate. The extracted factors have been named Risk, Enjoyment, User Friendliness, and Price, based on the scale items that load most heavily on them, and are shown with factor loadings in Table 2.

Table 1: Demographic Profile of Respondents

\begin{tabular}{|lccccc|}
\hline Gender & Female & Male & & & \\
& $(57 \%)$ & $(43 \%)$ & & $45-54$ & $55-64$ \\
Age & Under 24 & $25-34$ & $35-44$ & $(22.3 \%)$ & $(39.9 \%)$ \\
\hline Education & $(16.5 \%)$ & $(4.8 \%)$ & $(16.5 \%)$ & 4 year degree + \\
& no H.S. diploma & H.S. diploma & some college & 4 year degree & $(22 \%)$ \\
\hline Annual & $(1 \%)$ & $(9 \%)$ & $(32 \%)$ & $(35 \%)$ & $(25)$ \\
Household Income & Under $\$ 25,000$ & $\$ 25,001-50,000$ & $\$ 50,001-75,000$ & $\$ 75,001-100,000$ & Over $\$ 100,000$ \\
& $(14 \%)$ & $(35 \%)$ & $(24 \%)$ & $(10 \%)$ & $(14 \%)$ \\
\hline
\end{tabular}

\subsection{Discussion}

While it is not the purpose of this paper to report on the relative importance of each variable contained in the questionnaire, several findings of interest help frame the discussion on hygiene factors and motivators. Of particular interest are the variables that respondents felt most strongly about (based on mean scores of responses). The four variables reflecting the highest mean response relate to website navigability, convenience, impulse purchasing and enjoyment. The vast majority of respondents enjoys shopping on the internet, do so for convenience and comparison shopping, but do not make impulse purchases. Although website navigability was the single most important "hygiene factor", respondents also felt strongly about receiving unwanted email, and exhibited concerns about privacy and credit card security as well. While these are important findings, this paper addresses primarily the correlation amongst variables, and attempts to answer the question of whether the data (and internet shoppers opinions) can be better represented by grouping the variables according to satisfiers and dissatisfiers?

Based on the factor analysis of respondents' attitudes towards internet shopping, the data set analyzed reveals that although four factors were extracted, their appears to be intuitive support for the two-factor theory in helping to explain shopper satisfaction and dissatisfaction. The first factor, Risk, clearly represents a hygiene factor. If the shopper has concerns about product guarantees, misrepresentation, credit card vulnerability, privacy, delivery time, etc., the chances of a purchase are greatly reduced. In other words, high risk is a dissatisfier, but low risk is not necessarily a motivator. The same can be said for the third factor, User Friendliness. While the scale items loading on this factor do not represent intuitively close relationships, this factor appears to be measuring dissatisfiers as well. If the site is not navigable, product delivery cost is too high, or the perception of after sales service is not acceptable, purchase and user satisfaction are less likely to occur. However, as the previous discussion of the model revealed, even if an e-tailer were to alleviate these dissatisfiers, an internet purchase will not necessarily occur. A site could be perfectly designed, all risk eliminated, there could be free delivery and astounding after sales service, but if the purchaser is not interested in the products available, then a purchase is not likely.

Internet shopping satisfiers, or motivators to purchase, are more likely to be contained in the other two factors labeled Enjoyment and Price. A primary motivation for internet purchasing appears to lie in the ability of the shopper to comparison shop among e-tailers for (perhaps among other things) the best price. The second major source of purchasing motivation, Enjoyment, reflects the shoppers' quest for site or product uniqueness, purchase impulsivity, shopping convenience, and/or the desire NOT to talk to a sales representative (note negative loading of this scale item). While these results are not surprising, they are, for the most part, both intuitively appealing and operationally practicable. Internet retailers must therefore devote resources to not only attracting customers, but 
also to reducing user frustration and perceptions of risk. But where are the website atmospherics in all of this, i.e., are they motivators or hygiene factors? The answer, most probably, is both.

As discussed earlier, website atmospherics encompass a variety of existing and emerging technologies. As technologies mature, internet users come to expect them from websites, and if not present, their absence is a source of dissatisfaction. For example, an on-line retailer that does not accept major credit cards today would certainly be an exception, and would be a source of dissatisfaction for many would-be purchasers. At the same time, having the ability to accept credit cards does not currently give a competitive edge to most retailers, and is not, therefore, a motivator. Turn the clock back five years, however, and the same capability (to accept credit cards) could be a motivating force if a retailer's on-line competitors did not offer that service, provided the customer's perceptions of risk could be allayed. While credit card capabilities does not necessarily fall into an "atmospherics" category, the same line of reasoning applies for other website embellishments.

Table 2: Rotated Factor Matrix

\begin{tabular}{|c|c|c|c|c|}
\hline Scale Item & $\begin{array}{c}\text { (1) } \\
\text { Risk }\end{array}$ & $\begin{array}{c}(2) \\
\text { Enjoyment }\end{array}$ & $\begin{array}{c}\text { (3) } \\
\text { User } \\
\text { Friendliness }\end{array}$ & $\begin{array}{c}(4) \\
\text { Price }\end{array}$ \\
\hline Product guarantee on internet purchases & 0.7115 & & & \\
\hline Have seen the product somewhere else first & 0.6687 & & & \\
\hline Misrepresentation of product on internet & 0.6517 & & & \\
\hline Internet shopping frustration & 0.5999 & & & \\
\hline Credit card security & 0.5876 & & & \\
\hline Internet shopping privacy concerns & 0.5563 & & & \\
\hline Delivery time & 0.5379 & & & \\
\hline Receiving unwanted email & 0.4136 & & & \\
\hline Internet shopping enjoyment & & 0.6943 & & \\
\hline Only place product can be found & & 0.6817 & & \\
\hline Impulse purchases & & 0.6493 & & \\
\hline Internet shopping convenience & & 0.5615 & & \\
\hline Importance of talking to sales rep before purchase & & -0.5602 & & \\
\hline Internet site navigability & & & 0.6295 & \\
\hline High delivery cost & & & 0.5950 & \\
\hline Internet after sales service & & & 0.4547 & \\
\hline Comparison shopping before purchase & & & & 0.7615 \\
\hline Best prices are found on the internet & & & & 0.7176 \\
\hline
\end{tabular}

One such atmospheric innovation is aroma generation peripherals for computers. Applications range from video gaming, product demonstrations, and medical testing (see e.g. Aromajet.com; Digiscents, inc.; Trisenx). While such an atmospheric element can be a positive influence in a grocery store (fresh baked bread, ground coffee, etc.), the effect it will have on users at home or work are more difficult to ascertain (particularly if an intended scent is digitally misinterpreted by the generator). Further, one must wonder how long, if ever, aroma generators will be "standard issue" on computers, much like stereo speakers are now.

However, on-line retailers need to be prepared to incorporate the capability for users to augment their online experience. As Naumann and Jackson (1999:1) posit, "Customer satisfaction is derived by providing products with attributes that meet client expectation and satisfier characteristics that exceed their needs. However, companies should always remember that customer expectation is a factor that moves continuously upward." This continuous upward spiral of customer expectation offers another interpretation of the motivator/hygiene factor construct. Figure 2 illustrates the plot of expectations over time in the life-cycle of atmospheric innovations. 
Upon introduction, an atmospheric innovation may be a motivator, provided actual website performance meets/exceeds expectations. For instance, the introduction of streaming videos would be considered a motivator for some, provided the user's computer processor and internet connection could handle the bandwidth and speed requirements. As the innovation gains widespread popularity, and as long its growth in popularity is accompanied by concomitant growth in installed capability, it remains a motivator for those who use it. As the technology matures, and as users come to "expect" the innovation on a website, the embellishment "crosses the line" and moves from a motivator to a hygiene factor for those who fail to meet expectations. Web site developers / maintainers must continually upgrade to meet or exceed customer expectations.

However the expectations (and effects) of website atmospherics on shopper satisfaction are more difficult to assess than in the traditional retail environment. Previous studies on atmospherics in the conventional retail setting were often done in controlled, experimental settings. There are still many uncontrollable variables associated with internet retailing. While it is possible to monitor some aspects of internet shopper's behavior (does he/she fill the shopping cart but abandon it before checking out?), the majority of environmental variables are beyond the e-tailer's control. For instance, music played in traditional store settings has been found to be a motivator for some shoppers - it heightens the enjoyment of shopping, can increase purchases and the likelihood of the customer returning to the store. But does it have the same effect in an internet setting?

The same atmospheric embellishment: music streaming from a computer's speakers intended to subliminally influence a shoppers attitude and disposition to purchase. Clearly a motivator? But what if the user is shopping from his/her place of work and does not want to be caught, is shopping at home while the family is watching TV, or is connected with a slow modem and the streaming audio hinders the performance of the site? The effects of the atmospheric elements are now negated (at best), or even become dissatisfiers. Other critical issues such as monitor size, screen settings, browser type, internet connection speed, processor type and speed, etc., all influence the functionality of websites, and hence, the degree of user frustration or enjoyment.

Figure 2: Atmospheric Innovation Life-Cycle Performance vs. Expectations

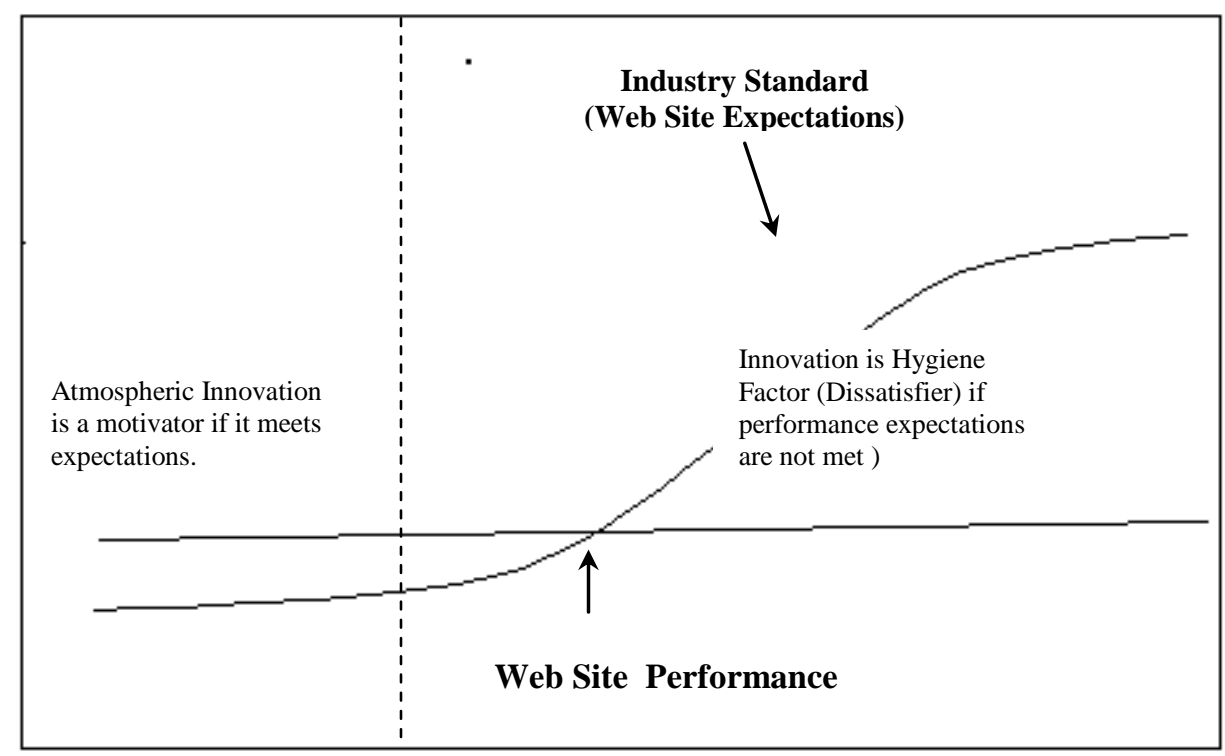

Adapted from Geoffrion, Leo D. (2001) 


\subsection{Conclusion}

Based on the mean responses of those surveyed, shoppers use the internet primarily for comparison shopping, convenience, and for finding the best price. The majority of respondents find internet shopping enjoyable, and the primary detractors from this enjoyment are poor website navigability, and perceptions of risk/security.

Despite differing methodology, this research shows remarkably consistent findings with previous research in the field of internet retailing. The grouping of variables loading on the factors of Risk, Enjoyment, User Friendliness, and Price fit neatly within the construct of Herzberg's two-factor theory of hygiene factors and motivators, and correlate highly with the results of Zhang and Von Dran (2000).

These findings reinforce the need for web retailers to reduce perceptions of risk and increase website functionality and quality of service (hygiene factors) to reduce user dissatisfaction. Importantly, however, e-tailers must also recognize that even if these hygiene factors are taken care of, the result is not necessarily user satisfaction or purchase. Efforts must also be directed at the motivators (Enjoyment, Price) in order to induce purchase and user satisfaction.

While this research takes another step towards verifying the relevance of the two-factor theory, future research is needed to confirm factor structures. It would also be useful to conduct the same study in several years to determine whether factor structure changes over time. Future research should also be directed at isolating, in a more controlled, experimental setting, the specific effects of web site atmospheric elements on shopper attitude and behavior, as has been done extensively in the traditional retail environment.

\section{References}

1. Bellizzi, J.A., A.E. Crowley and R. W. Hasty (1983). "The effects of color in store design." Journal of Retailing, 59, (Spring), 21-45.

2. Bitner, Mary Jo (1992). "Servicescapes: the impact of physical surroundings on employee responses." Journal of Marketing, 56, (April), 57-71.

3. Bruner, Gordon C. (1990). "Music, mood, and marketing." Journal of Marketing, 54, (October), 94-104

4. d'Astous, Alain (2000). "Irritating aspects of the shopping environment". Journal of Business Research, 49 149-156.

5. Geoffrion, Leo D. (2001) "The life-cycle for technology innovation." http://www.skidmore.edu/ ldg/ future/innovation-lifecycle.html

6. Hanson, Ward. (2000). Internet Marketing, Southwestern Publishing, Cincinnati.

7. Hui, Michael K. and John E. G. Bateson (1991). "Perceived control and the effects of crowding and consumer choice on the service experience." Journal of Consumer Research, 18, (September), 174-184.

8. Kellaris James J. and Robert J. Kent (1992). "The influence of music on consumers' temporal perceptions: does time fly when you're having fun?". Journal of Consumer Psychology 1 (4), 365-376

9. Kelley, Craig (2001) "An exploratory investigation of the irritants of web site atmospherics." Proceedings, 2001 SMA conference.

10. Naumann, Earl and Donald Jackson Jr. (1999). "One more time: how do you satisfy customers?" Business Horizons, 42, 3 71(6).

11. Spangenberg, Eric R., Ayn E. Crowley, and Pamela W. Henderson (1996). "Improving the store environment: do olfactory cues affect evaluations and behaviors?" Journal of Marketing, 60, (April) 67-80

12. Turley, L.W. and R. E. Milliman (2000) "Atmospheric effects on shopping behavior: a review of the experimental evidence.” Journal of Business Research , 49, 193-211.

13. Yalch, R. and e. Spangenberg. (1990). "Effects of store music on shopping behavior." Journal of Services Marketing, Winter.

14. Zhang, Ping and Gisela M. Von Dran. (2000) "Satisfiers and dissatisfiers: A two-factor model for website design and evaluation." Journal of the American Society for Information Science, 51, 14, 1253(16). 
This survey is being conducted by students at the College of Charleston School of Business and Economics. All responses will be kept strictly confidential. Your contact number is requested in case clarification of response is needed. Thank you for participating.

\section{Section A}

Have you ever shopped on the internet before? (not necessarily purchased) $\quad \theta \square$ Yes $\quad \theta \square$ No (If no, do not complete survey)

When internet shopping, where do you usually access the Internet?

$\theta \square$ Home $\quad \theta \square$ Work or School $\quad \theta \square$ Other (specify)

When internet shopping, how are you connected to the Internet? $\theta \square$ Telephone line up to 56k $\theta \square$ Cable modem $\theta \square$ Network Connection $\theta \square$ Telephone line over 56k $\theta \square$ Don't know $\quad \theta \square$ Other

Approximately how many hours a day do you spend online?

$\theta \square$ Less than $1 \quad \theta \square 1-3 \quad \theta \square 3-5 \quad \theta \square$ over 5

Do you have your own personal web page? $\quad \theta \square$ Yes $\quad \theta \square$ No

Do you have a computer at home connected to the internet? $\theta \square$ Yes $\quad \theta \square$ No

What is your gender? $\quad \theta \square$ Male $\theta \square$ Female

What is your age? $\theta \square$ 18-24 $\quad \theta \square 25-34 \quad \theta \square 35-44 \quad \square 45-54 \quad \theta \quad \square 5+$

Do you have any children over the age of 4 living at home? $\theta \square$ Yes $\quad \theta \square$ No

What type of products/services do you shop for or purchase on the Internet? (Check all that apply)

$\theta \square$ Electronics $\quad \theta \square$ Travel $\quad \theta \square$ Financial $\quad \theta \square$ Books/ C.D's

$\theta \square$ Food/health $\quad \theta \square$ Cars $\theta \square$ Clothing/jewelry $\quad \theta \square$ Other (specify)

Have you ever purchased anything over the internet? $\quad \theta \square$ Yes $\theta \square$ No $\quad$ (If NO, proceed to Section B)

How often to you purchase over the internet?

$\theta \square$ regularly $\quad \theta \square$ occasionally $\quad \theta \square$ seldom $\quad \theta \square$ only once

Are your internet purchases primarily for: $\theta \square$ business use? $\quad \theta \square$ personal use?

Approximately how much have you spent on internet purchases in the past year?

$\theta \square$ under $\$ 100 \quad \theta \square \$ 101-\$ 500 \quad \theta \square \$ 501-\$ 1000 \quad \theta \square \$ 1001-\$ 10,000 \quad \theta \square$ over $\$ 10,000$

Have you ever had a bad experience with internet shopping? $\theta \square$ Yes $\quad \theta \square$ No

What was the cause of this bad experience (check all that apply)?
$\theta \square$ Customer service
$\theta \square$ Product delivery
$\theta \square$ Quality of product
$\theta \square$ Process too slow
$\theta \square$ Network crash
$\theta \square$ Site too complicated
$\theta \square$ Misrepresentation
$\theta \square$ Billing problems
$\theta \square$ Other (specify)

Would you purchase from the site again?

$\theta \square$ Yes

$\theta \square$ No

\section{PLEASE COMPLETE SECTION B ON NEXT PAGE}




\section{Section B}

I often can't remember the web address of a site I want to visit

The best prices can usually be found on the internet

I am very concerned about privacy when internet shopping

It is safe to use my credit card for internet purchases

I can always find what I am shopping for on the internet

I won't buy from a site if it is cluttered or complicated

I won't purchase if I can't find a specific product or brand

I don't go back to a site if a product is out of stock

I find internet shopping frustrating

I would prefer to talk to representative before an internet purchase

I believe that after sales service on the internet is excellent

Technical support for internet purchases is very good

I shop on the internet mainly for convenience

It takes too long to get products delivered with internet purchases

I enjoy shopping on the internet

Delivery charges are very reasonable for internet purchases

Product guarantees are not as reliable on internet purchases

It is difficult to return products purchased over the internet

Products are more easily misrepresented on the internet

It takes too long to fill out order forms on the internet

I won't purchase unless I have heard of the company before

I have made an impulse (banner induced) purchase on the internet

I won't buy a product unless I have seen it somewhere else first

Sometimes the internet is the only place I can find a product

I visit more then one site before making an internet purchase

What is the highest level of education you have completed?

$\theta \square$ Less than H.S. diploma $\quad \theta \square$ H.S. Diploma

$\theta \square 2$ year degree

$\theta \square 4$ year degree

\begin{tabular}{|c|c|c|c|c|}
\hline $\begin{array}{c}\text { Strongly } \\
\text { Agree }\end{array}$ & $\begin{array}{l}\text { Mostly } \\
\text { agree }\end{array}$ & $\begin{array}{l}\text { Neither } \\
\text { agree nor } \\
\text { disagree }\end{array}$ & $\begin{array}{c}\text { Mostly } \\
\text { Disagree }\end{array}$ & $\begin{array}{l}\text { Strongly } \\
\text { Disagree }\end{array}$ \\
\hline$\theta \square$ & $\square$ & $\theta \square$ & $\theta \square$ & $\theta \square$ \\
\hline$\theta \square$ & $\theta \square$ & $\theta \square$ & $\theta \square$ & $\theta \square$ \\
\hline$\theta \square$ & $\theta \square$ & $\theta \square$ & $\theta \square$ & $\theta \square$ \\
\hline$\theta \square$ & $\theta \square$ & $\theta \square$ & $\theta \square$ & $\theta \square$ \\
\hline$\theta \square$ & $\theta \square$ & $\theta \square$ & $\theta \square$ & $\theta \square$ \\
\hline$\theta \square$ & $\theta \square$ & $\theta \square$ & $\theta \square$ & $\theta \square$ \\
\hline$\theta \square$ & $\theta \square$ & $\theta \square$ & $\theta \square$ & $\theta \square$ \\
\hline$\theta \square$ & $\theta \square$ & $\theta \square$ & $\theta \square$ & $\theta \square$ \\
\hline $\begin{array}{c}\text { Strongly } \\
\text { Agree }\end{array}$ & $\begin{array}{l}\text { Mostly } \\
\text { agree }\end{array}$ & $\begin{array}{l}\text { Neither } \\
\text { agree nor } \\
\text { disagree }\end{array}$ & $\begin{array}{c}\text { Mostly } \\
\text { Disagree }\end{array}$ & $\begin{array}{l}\text { Strongly } \\
\text { Disagree }\end{array}$ \\
\hline$\theta \square$ & $\theta \square$ & $\theta \square$ & $\theta \square$ & $\theta \square$ \\
\hline$\theta \square$ & $\theta \square$ & $\theta \square$ & $\theta \square$ & $\theta \square$ \\
\hline$\theta \square$ & $\theta \square$ & $\theta \square$ & $\theta \square$ & $\theta \square$ \\
\hline$\theta \square$ & $\theta \square$ & $\theta \square$ & $\theta \square$ & $\theta \square$ \\
\hline$\theta \square$ & $\theta \square$ & $\theta \square$ & $\theta \square$ & $\theta \square$ \\
\hline$\theta \square$ & $\theta \square$ & $\theta \square$ & $\theta \square$ & $\theta \square$ \\
\hline$\theta \square$ & $\theta \square$ & $\theta \square$ & $\theta \square$ & $\theta \square$ \\
\hline$\theta \square$ & $\theta \square$ & $\theta \square$ & $\theta \square$ & $\theta \square$ \\
\hline $\begin{array}{l}\text { Strongly } \\
\text { Agree }\end{array}$ & $\begin{array}{l}\text { Mostly } \\
\text { agree }\end{array}$ & $\begin{array}{l}\text { Neither } \\
\text { agree nor } \\
\text { disagree }\end{array}$ & $\begin{array}{c}\text { Mostly } \\
\text { Disagree }\end{array}$ & $\begin{array}{l}\text { Strongly } \\
\text { Disagree }\end{array}$ \\
\hline$\theta \square$ & $\theta \square$ & $\theta \square$ & $\theta \square$ & $\theta \square$ \\
\hline$\theta \square$ & $\theta \square$ & $\theta \square$ & $\theta \square$ & $\theta \square$ \\
\hline$\theta \square$ & $\theta \square$ & $\theta \square$ & $\theta \square$ & $\theta \square$ \\
\hline$\theta \square$ & $\theta \square$ & $\theta \square$ & $\theta \square$ & $\theta \square$ \\
\hline$\theta \square$ & $\theta \square$ & $\theta \square$ & $\theta \square$ & $\theta \square$ \\
\hline$\theta \square$ & $\theta \square$ & $\theta \square$ & $\theta \square$ & $\theta \square$ \\
\hline$\theta \square$ & $\theta \square$ & $\theta \square$ & $\theta \square$ & $\theta \square$ \\
\hline$\theta \square$ & $\theta \square$ & $\theta \square$ & $\theta \square$ & $\theta \square$ \\
\hline$\theta \square$ & $\theta \square$ & $\theta \square$ & $\theta \square$ & $\theta \square$ \\
\hline
\end{tabular}

What is your approximate annual household income?

$\theta \square$ under $\$ 25,000 \theta \square \$ 25,001-50,000$

$\theta \square \$ 50,001-75,000$

$\theta \square \$ 75,001-100,000 \quad \theta \square$ over $\$ 100,001$ 
Notes 